\title{
PSCA polymorphisms and gastric cancer susceptibility in an eastern Chinese population
}

\author{
Li-Xin Qiu ${ }^{1,2, *}$, Lei Cheng ${ }^{2, *}$, Jing He ${ }^{3, *}$, Zhi-Rui Zhou ${ }^{4}$, Meng-Yun Wang ${ }^{2}$, Fei Zhou ${ }^{2}$, \\ Wei-Jian Guo ${ }^{1}$, Jin Li ${ }^{1}$, Meng-Hong Sun ${ }^{5}$, Xiao-Yan Zhou ${ }^{5}$, Ya-Nong Wang ${ }^{6}$, Ya-Jun \\ Yang $^{7,8}$, Jiu-Cun Wang ${ }^{7,8}$, Li Jin ${ }^{7,8}$, Xiao-Dong Zhu ${ }^{1}$ and Qing-Yi Wei ${ }^{2,9}$ \\ ${ }^{1}$ Department of Medical Oncology, Fudan University Shanghai Cancer Center, Department of Oncology, Shanghai Medical \\ College, Fudan University, Shanghai, China \\ ${ }^{2}$ Cancer Institute, Collaborative Innovation Center for Cancer Medicine, Fudan University Shanghai Cancer Center, Shanghai, \\ China \\ ${ }^{3}$ Department of Pediatric Surgery, Guangzhou Women and Children's Medical Center, Guangzhou Medical University, \\ Guangzhou, China \\ ${ }^{4}$ Department of Radiation Oncology, Fudan University Shanghai Cancer Center, Department of Oncology, Shanghai Medical \\ College, Fudan University, Shanghai, China \\ ${ }^{5}$ Department of Pathology, Fudan University Shanghai Cancer Center, Shanghai, China \\ ${ }^{6}$ Department of Gastric Cancer \& Soft Tissue Sarcoma Surgery, Fudan University Shanghai Cancer Center, Shanghai, China \\ ${ }^{7}$ Ministry of Education Key Laboratory of Contemporary Anthropology and State Key Laboratory of Genetic Engineering, \\ School of Life Sciences, Fudan University, Shanghai, China \\ ${ }^{8}$ Fudan-Taizhou Institute of Health Sciences, Taizhou, China \\ ${ }^{9}$ Duke Cancer Institute, Duke University Medical Center, and Department of Medicine, Duke University School of Medicine, \\ Durham, NC, USA \\ * These authors have contributed equally to this work \\ Correspondence to: Xiao-Dong Zhu, email: xddr@netease.com
}

Qing-Yi Wei, email: weiqingyi@yahoo.com or qingyi.wei@duke.edu

Keywords: PSCA, polymorphism, gastric cancer, genetic susceptibility

Received: October 09, $2015 \quad$ Accepted: January 19, $2016 \quad$ Published: February 02, 2016

\section{ABSTRACT}

The prostate stem cell antigen (PSCA) gene, which encodes a prostate-specific antigen (PSA), was identified as a gene involved in cell adhesion and proliferation. The associations between the PSCA rs2294008 and rs2976392 single nucleotide polymorphisms (SNPs) and gastric cancer (GCa) susceptibility were still controversial. To derive a more precise estimation of the associations, we conducted a case-control study of 1,124 cases and 1,192 controls in an eastern Chinese population. We found that the rs2294008T variant genotypes were associated with an increased GCa risk in this study population (CT vs CC, OR=1.59, 95\% CI $=1.33-1.89$ and CT+TT vs CC, $O R=1.38,95 \% C I=1.17-1.62)$. For SNP rs2976392, the variant $A$ genotypes were also associated with an increased GCa risk (AG vs GG, $O R=1.61,95 \% \mathrm{CI}=1.35-1.91$ and $A G+A A$ vs $G G, O R=1.47,95 \% C I=1.25-1.74)$. The results were further validated by a meta-analysis. In conclusion, the results indicated that the PSCA rs2294008 T and rs2976392 A alleles were low-penetrate risk factors for GCa in this study population. However, large and well-designed studies are warranted to validate our findings.

\section{INTRODUCTION}

Gastric cancer (GCa) is the most frequently occurring cancer and one of the leading causes of cancerrelated deaths. There were 951,600 new GCa cases and 723,100 deaths in 2012 , accounting for $8 \%$ of the cancer cases and $10 \%$ of cancer deaths in the world, respectively [1]. Therefore, GCa has become a major public health challenge. While the mechanism of gastric carcinogenesis is still not fully understood, it has been suggested that environmental factors and low-penetrance susceptibility genes may be important in the etiology of GCa. A high rate 
of Helicobacter pylori $(H P)$ infection might be a potential risk factor for an increased $\mathrm{GCa}$ risk in developing countries $(70-90 \%)$ than in developed countries $(25-50 \%)$ $[2,3]$. However, only few $H P$ carriers will develop GCa; therefore, other factors must play a role in GCa risk. Lifestyle factors such as tobacco smoking, alcohol use and dietary habits are also likely to be potential risk factors for GCa [4]. Although genetic factors for GCa risk are still not fully understood, some recent success in identifying significant associations between genetic variants and $\mathrm{GCa}$ risk is encouraging [5-9], and it is necessary to confirm those genetic factors that have been reported to play a role in $\mathrm{GCa}$ risk.

The prostate stem cell antigen (PSCA) gene, which encodes a prostate-specific antigen (PSA), was identified as a gene involved in cell adhesion, proliferation and patient survival $[10,11]$. PSCA is mainly expressed in the region of isthmus/neck, but its expression was undetectable in GCa tumor tissues [12], suggesting a loss of tumor-suppressor effect of PSCA in GCa. In addition, its biological role in cancer advancement was also reported by published in vivo functional studies [13, 14]. Therefore, it is necessary to investigate the role of $P S C A$ genetic variants in the etiology of GCa. Importantly, several GWAS studies have demonstrated an association between $P S C A$ variants and cancer susceptibility $[13,15$, 16]. One GWAS study in Korea and Japanese populations reported that two SNPs in the PSCA gene (rs2294008 C > T and rs2976392 G>A) were associated with an increased $\mathrm{GCa}$ risk [13]. However, these associations were not replicated in the subsequent replication studies $[17,18]$.

To further confirm the associations between PSCA rs2294008 and rs2976392 SNPs and GCa risk, we conducted a replication study in a large Eastern Chinese population and also performed a meta-analysis with published studies.

\section{RESULTS}

Baseline characteristics of individuals included in this study were consistent with those described in our previous study [19], but one sample in cases and four samples in controls failed to be genotyped. Thus, the final analysis included 1,124 GCa patients and 1,192 cancerfree controls (supplemental Table 1). Subjects were well matched by age and sex with more smokers and drinkers in the controls, but these variables were further adjusted in the following multivariate analysis. The rs 2294008 and rs2976392 appeared to be in a high linkage disequilibrium $\left(\mathrm{r}^{2}=0.969\right)$.

The allele frequencies of SNPs rs2294008 and rs2976392 in cases and controls and their associations with GCa risk are presented in Table1. The variant rs2294008T genotypes were associated with an increased risk of $\mathrm{GCa}$ ( $\mathrm{CT}$ vs $\mathrm{CC}, \mathrm{OR}=1.59,95 \% \mathrm{CI}=1.33-1.89$ and $\mathrm{CT}+\mathrm{TT}$ vs $\mathrm{CC}, \mathrm{OR}=1.38,95 \% \mathrm{CI}=1.17-1.62)$. For SNP rs2976392, the variant A genotypes were also associated with an increased $\mathrm{GCa}$ risk ( $\mathrm{AG}$ vs $\mathrm{GG}, \mathrm{OR}=1.61,95 \% \mathrm{CI}=1.35$ 1.91 and $\mathrm{AG}+\mathrm{AA}$ vs $\mathrm{GG}, \mathrm{OR}=1.47,95 \% \mathrm{CI}=1.25-1.74)$. When these two SNPs were combined, subjects who carried more than one risk alleles exhibited a significantly increased risk of $\mathrm{GCa}(\mathrm{OR}=1.35,95 \% \mathrm{CI}=1.14-1.59)$, compared with those who did not carry any risk alleles.

In the stratified analysis presented in Table 2, we found that the associations between the SNP rs2294008 and $\mathrm{GCa}$ risk remained significant in dominant models for subgroups of $<=59$ years $(\mathrm{OR}=1.53,95 \% \mathrm{CI}=1.22-1.93)$, males $(\mathrm{OR}=1.34,95 \% \mathrm{CI}=1.10-1.63)$, females $(\mathrm{OR}=1.52$, $95 \% \mathrm{CI}=1.13-2.06)$, never smoking $(\mathrm{OR}=1.54,95 \%$ $\mathrm{CI}=1.23-1.92),<=25$ pack years $(\mathrm{OR}=1.49,95 \% \mathrm{CI}=1.06$ $2.11)$, never drinking $(\mathrm{OR}=1.41,95 \% \mathrm{CI}=1.16-1.70)$, and NGCA tumor site $(\mathrm{OR}=1.45,95 \% \mathrm{CI}=1.21-1.74)$. We also found that significant associations of rs2976392 with an increased GCa risk remained in the subgroups of age, sex, smoking status, drinking status and tumor site. Consistent with stratified results of rs2294008, the combined effects of these two SNPs on an increased GCa risk were significant, in subgroups of $<=59$ years $(\mathrm{OR}=1.49$, $95 \% \mathrm{CI}=1.19-1.88)$, males $(\mathrm{OR}=1.30,95 \% \mathrm{CI}=1.07$ 1.58), females $(\mathrm{OR}=1.53$, 95\% $\mathrm{CI}=1.13-2.07)$, never smoking $(\mathrm{OR}=1.48,95 \% \mathrm{CI}=1.19-1.85),<=25$ pack years $(\mathrm{OR}=1.45,95 \% \mathrm{CI}=1.02-2.05)$, never drinking $(\mathrm{OR}=1.36$, $95 \% \mathrm{CI}=1.12-1.65)$, and NGCA tumor site $(\mathrm{OR}=1.40$, 95\% CI=1.17-1.68) (Table 2).

Then, we performed a min meta-analysis, including the present study, of 19 studies [17, 18, 26-42]. Pooled data indicated that both PSCA rs2294008 and rs2976392 SNPs were strongly associated with an increased GCa risk (Table 3). For rs2294008 (14226 cases and 14033 controls): heterozygous model: $\mathrm{OR}=1.52,95 \% \mathrm{CI}=1.11$ 2.10; homozygous model: $\mathrm{OR}=1.75,95 \% \mathrm{CI}=1.50-2.04$; dominant model: $\mathrm{OR}=1.55,95 \% \mathrm{CI}=1.38-1.75$ (also see Figure 1). For rs2976392 (7966 cases and 6860 controls): heterozygous model: $\mathrm{OR}=1.48,95 \% \mathrm{CI}=1.26$ 1.74; homozygous model: $\mathrm{OR}=1.60,95 \% \mathrm{CI}=1.16-2.21$; dominant model: $\mathrm{OR}=1.53,95 \% \mathrm{CI}=1.27-1.84$ ) (also see Figure 2) without significant publication bias. However, significant heterogeneities across studies were present in these genetic models. Thus, we performed a sensitive analysis to assess the effects of each study on pooled results. Pooled ORs were not affected by omitting each of studies at a time (data not shown), which suggests that the results are robust. The required information size were estimated with $80 \%$ power, $5 \%$ two-side alpha, $10 \%$ reduced relative risk and heterogeneity correlation based on the results of traditional meta-analysis. the TSA analysis suggested that cumulative information size of dominant models for rs2294008 (28259) had reached the cumulative information size (18726). Other metaanalysis did not reach but was not far from the required information size. Moreover, the Lan DeMets sequential monitoring boundary for benefit of wild-type alleles was 
Table 1: Logistic regression analysis of associations between PSCA genotypes and gastric cancer risk in an eastern Chinese population

\begin{tabular}{|c|c|c|c|c|c|c|c|c|}
\hline Variants & Genotype & $\begin{array}{l}\text { Cases } \\
(\mathrm{N}=1124)\end{array}$ & $\begin{array}{l}\text { Controls } \\
(\mathrm{N}=1192)\end{array}$ & $P^{\mathrm{a}}$ & $\begin{array}{l}\text { Crude OR } \\
(95 \% \text { CI) }\end{array}$ & $P$ & $\begin{array}{l}\text { Adjusted OR } \\
(95 \% \text { CI })^{b}\end{array}$ & $P^{b}$ \\
\hline \multicolumn{9}{|l|}{ rs2294008 } \\
\hline & $\mathrm{CC}$ & $537(47.8)$ & $663(55.6)$ & $<0.0001^{\mathrm{c}}$ & 1.00 & & 1.00 & \\
\hline & $\mathrm{CT}$ & $489(43.5)$ & $383(32.1)$ & & $1.58(1.32-1.88)$ & $<0.0001$ & $1.59(1.33-1.89)$ & $<0.0001$ \\
\hline & $\mathrm{TT}$ & $98(8.7)$ & $146(12.3)$ & & $0.83(0.63-1.10)$ & 0.189 & $0.83(0.62-1.10)$ & 0.185 \\
\hline & $\mathrm{CT} / \mathrm{TT}$ & $587(52.2)$ & $529(44.4)$ & $0.0002^{\mathrm{d}}$ & $1.37(1.16-1.61)$ & 0.0002 & $1.38(1.17-1.62)$ & 0.0001 \\
\hline \multicolumn{9}{|l|}{ rs2976392 } \\
\hline & GG & $535(47.6)$ & $682(57.2)$ & $<0.0001^{\mathrm{c}}$ & 1.00 & & 1.00 & \\
\hline & AG & $488(43.4)$ & $388(32.6)$ & & $1.60(1.35-1.91)$ & $<0.0001$ & $1.61(1.35-1.91)$ & $<0.0001$ \\
\hline & AA & $101(9.0)$ & $122(10.2)$ & & $1.06(0.79-1.41)$ & 0.713 & $1.05(0.79-1.41)$ & 0.723 \\
\hline & $\mathrm{AG} / \mathrm{AA}$ & $589(52.4)$ & $510(42.8)$ & $<0.0001^{\mathrm{d}}$ & $1.47(1.25-1.73)$ & $<0.0001$ & $1.47(1.25-1.74)$ & $<0.0001$ \\
\hline \multicolumn{9}{|c|}{ Combined effect of risk genotypes } \\
\hline & 0 & $534(47.5)$ & $654(54.9)$ & $0.0004^{\mathrm{d}}$ & 1.00 & & 1.00 & \\
\hline & $\geq 1$ & $590(52.5)$ & $538(45.1)$ & & $1.34(1.14-1.58)$ & 0.0004 & $1.35(1.14-1.59)$ & 0.0004 \\
\hline
\end{tabular}

CI, confidence interval; OR, odds ratio

${ }^{a}$ Chi square test for genotype distributions between cases and controls

${ }^{\mathrm{b}}$ Adjusted for age, sex, smoking and drinking status in logistic regression models

$c$ for additive genetic models

d for dominant genetic models

Table 2: Stratification analysis for the associations between selected PSCA polymorphisms and GC risk in an eastern Chinese population

\begin{tabular}{|c|c|c|c|c|c|c|c|c|c|c|c|c|}
\hline \multirow[t]{2}{*}{ Variables } & \multicolumn{2}{|c|}{$\begin{array}{l}\text { rs2294008 } \\
\text { (cases/controls) }\end{array}$} & \multirow[t]{2}{*}{$\begin{array}{l}\text { Adjusted OR } \\
(95 \% \mathrm{CI})\end{array}$} & \multirow[t]{2}{*}{$P^{\mathrm{a}}$} & \multicolumn{2}{|c|}{$\begin{array}{l}\text { rs2976392 } \\
\text { (cases/controls) }\end{array}$} & \multirow[t]{2}{*}{$\begin{array}{l}\text { Adjusted OR } \\
(95 \% \text { CI })\end{array}$} & \multirow[t]{2}{*}{$P^{\mathrm{a}}$} & \multicolumn{2}{|c|}{$\begin{array}{l}\text { Combined effect of risk genotypes } \\
\text { (cases/controls) }\end{array}$} & \multirow[t]{2}{*}{$\begin{array}{l}\text { Adjusted OR } \\
(95 \% \mathrm{CI})\end{array}$} & \multirow[t]{2}{*}{$P^{\mathrm{a}}$} \\
\hline & $\mathrm{CC}$ & CT/TT & & & GG & AG/AA & & & 0 & $\geq 1$ & & \\
\hline \multicolumn{13}{|c|}{ Median age, yr } \\
\hline$\leq 59$ & $264 / 341$ & $314 / 265$ & $1.53(1.22-1.93)$ & 0.0003 & $262 / 346$ & $316 / 260$ & $1.61(1.28-2.02)$ & $<0.0001$ & $262 / 335$ & $316 / 271$ & $1.49(1.19-1.88)$ & 0.0006 \\
\hline$>59$ & $273 / 322$ & $273 / 264$ & $1.22(0.96-1.55)$ & 0.098 & $273 / 336$ & $273 / 250$ & $1.34(1.06-1.70)$ & 0.015 & $272 / 319$ & $274 / 267$ & $1.21(0.95-1.53)$ & 0.122 \\
\hline \multicolumn{13}{|l|}{ Sex } \\
\hline Males & $388 / 460$ & $412 / 365$ & $1.34(1.10-1.63)$ & 0.004 & $387 / 476$ & $413 / 349$ & $1.45(1.19-1.77)$ & 0.0002 & $386 / 452$ & $414 / 373$ & $1.30(1.07-1.58)$ & 0.010 \\
\hline Females & $149 / 203$ & $175 / 164$ & $1.52(1.13-2.06)$ & 0.007 & $148 / 206$ & $176 / 161$ & $1.59(1.17-2.15)$ & 0.003 & $148 / 202$ & $176 / 165$ & $1.53(1.13-2.07)$ & 0.006 \\
\hline \multicolumn{13}{|c|}{ Smoking status } \\
\hline Never & $319 / 346$ & $366 / 260$ & $1.54(1.23-1.92)$ & 0.0001 & $318 / 350$ & $367 / 256$ & $1.59(1.28-1.99)$ & $<0.0001$ & $318 / 340$ & $367 / 266$ & $1.48(1.19-1.85)$ & 0.0005 \\
\hline Ever & $218 / 317$ & $221 / 269$ & $1.21(0.94-1.55)$ & 0.134 & $217 / 332$ & $222 / 254$ & $1.35(1.05-1.74)$ & 0.019 & $216 / 314$ & $223 / 272$ & $1.21(0.94-1.55)$ & 0.141 \\
\hline \multicolumn{13}{|l|}{ Pack-year } \\
\hline 0 & $319 / 346$ & $366 / 260$ & $1.54(1.23-1.92)$ & 0.0001 & $318 / 350$ & $367 / 256$ & $1.59(1.28-1.99)$ & $<0.0001$ & $318 / 340$ & $367 / 266$ & $1.48(1.19-1.85)$ & 0.0005 \\
\hline $\begin{array}{r}\leq 25 \\
\text { (mean) }\end{array}$ & $104 / 188$ & $123 / 165$ & $1.49(1.06-2.11)$ & 0.023 & $104 / 192$ & $123 / 161$ & $1.59(1.12-2.25)$ & 0.009 & $104 / 185$ & $123 / 168$ & $1.45(1.02-2.05)$ & 0.036 \\
\hline$>25$ (mean) & $114 / 129$ & $98 / 104$ & $1.01(0.68-1.51)$ & 0.948 & $113 / 140$ & $99 / 93$ & $1.23(0.83-1.83)$ & 0.309 & $112 / 129$ & $100 / 104$ & $1.05(0.71-1.56)$ & 0.799 \\
\hline \multicolumn{13}{|c|}{ Drinking status } \\
\hline Never & $408 / 475$ & $446 / 373$ & $1.41(1.16-1.70)$ & 0.0005 & $406 / 485$ & $448 / 363$ & $1.49(1.23-1.80)$ & $<0.0001$ & $406 / 467$ & $448 / 381$ & $1.36(1.12-1.65)$ & 0.002 \\
\hline Ever & $129 / 188$ & $141 / 156$ & $1.32(0.96-1.82)$ & 0.087 & $129 / 197$ & $141 / 147$ & $1.47(1.07-2.03)$ & 0.019 & $128 / 187$ & $142 / 157$ & $1.33(0.96-1.83)$ & 0.084 \\
\hline \multicolumn{13}{|l|}{ Tumor site } \\
\hline GCA & $158 / 663$ & $147 / 529$ & $1.19(0.92-1.53)$ & 0.193 & $155 / 682$ & $150 / 510$ & $1.32(1.02-1.70)$ & 0.034 & $155 / 654$ & $150 / 538$ & $1.19(0.92-1.54)$ & 0.176 \\
\hline NGCA & $379 / 663$ & $440 / 529$ & $1.45(1.21-1.74)$ & $<0.0001$ & $380 / 682$ & $439 / 510$ & $1.53(1.28-1.83)$ & $<0.0001$ & $379 / 654$ & $440 / 538$ & $1.40(1.17-1.68)$ & 0.0002 \\
\hline
\end{tabular}


Table 3: Meta-analysis results for the associations between PSCA SNPs and GCa risk

\begin{tabular}{clllllll}
\hline Comparison & No. of studies & No. of subjects & OR (95\% CI) & $\boldsymbol{P}$ & $\boldsymbol{I}^{\mathbf{2}}$ & Model & $\boldsymbol{P}_{\text {bias }}$ \\
\hline rs2294008 & & & & & & & \\
CT vs. CC & 19 & 22185 & $1.52(1.11-2.10)$ & 0.01 & $95.90 \%$ & Random & 0.972 \\
TT vs. CC & 19 & 16049 & $1.75(1.50-2.04)$ & $<0.001$ & $71.70 \%$ & Random & 0.506 \\
CT/TT vs. CC & 19 & 28259 & $1.55(1.38-1.75)$ & $<0.001$ & $74.10 \%$ & Random & 0.054 \\
rs2976392 & & & & & & & \\
AG vs. GG & 11 & 12175 & $1.48(1.26-1.74)$ & $<0.001$ & $73.40 \%$ & Random 0.392 \\
AA vs. GG & 11 & 8419 & $1.60(1.16-2.21$ & $<0.001$ & $84.40 \%$ & Random 0.392 \\
AA/AG vs. GG & 11 & 14826 & $1.53(1.27-1.84)$ & $<0.001$ & $81.80 \%$ & Random 0.243 \\
\hline
\end{tabular}

$P_{\text {bias }}: P$ value for publication bias

crossed by cumulative results in all genetic models except for heterozygous models for rs2294008, indicating the results in our meta-analysis are conclusive and reliable. In addition, it was informed by sequential meta-analysis that results of the present study increased the cumulative $\mathrm{Z}$ score and therefore strengthened the positive evidence that rs2294008T and rs2976392A variants did have an effect on $\mathrm{GCa}$ risk (Figure 3A and 3B).

\section{DISCUSSION}

In addition to environmental and lifestyle factors for GCa risk, genetic factors are also important in identifying at-risk populations for prevention of GCa. Although PSCA is mainly expressed in the isthmus/neck region of the stomach where the GCa often occurs [13], it is interesting that PSCA expression is suppressed in GCa tumor tissues.

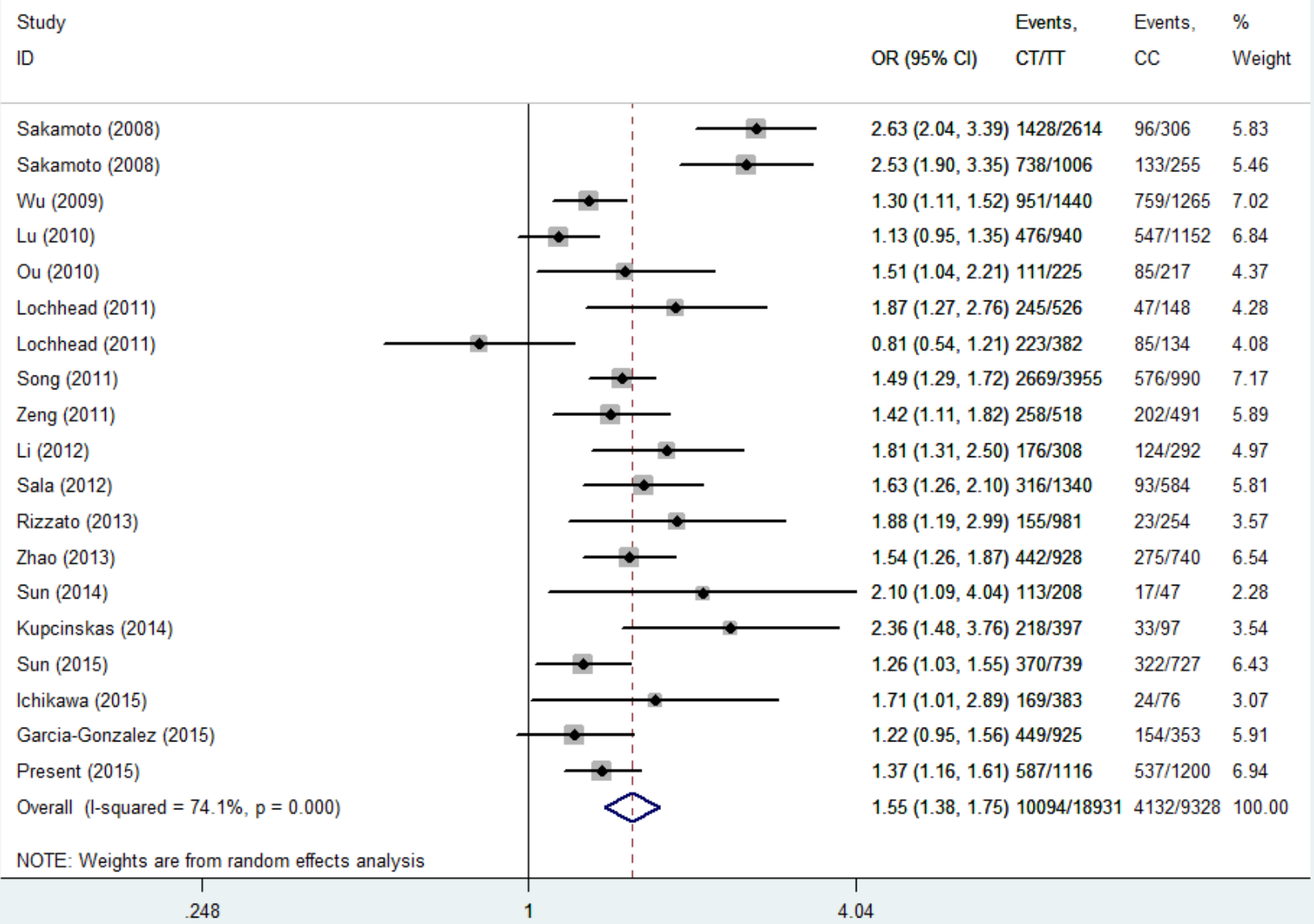

Figure1: Meta-analysis for the association between PSCA rs2294008 SNP and GCa risk in a dominant genetic model. 


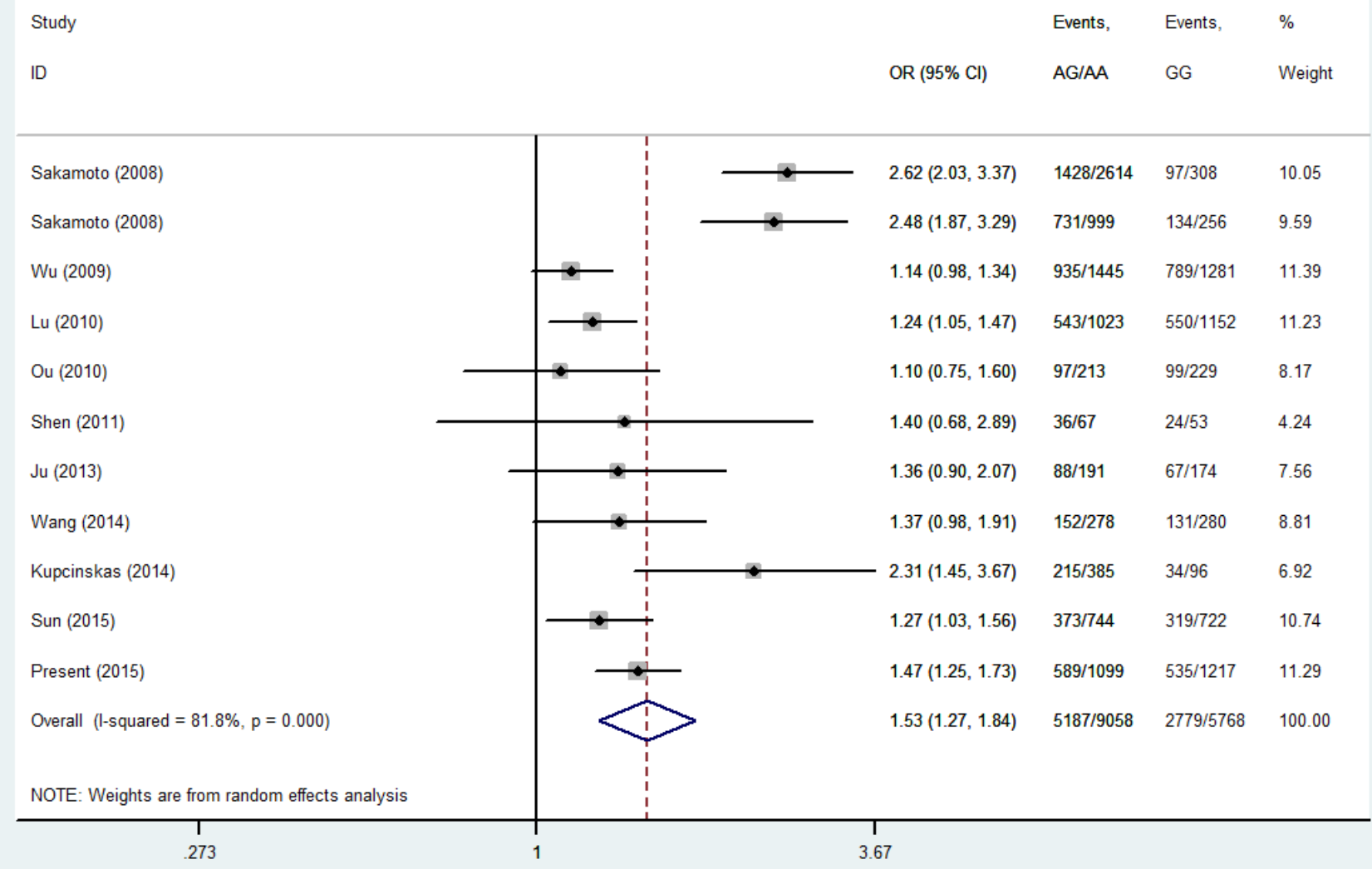

Figure 2: Meta-analysis for the association between PSCA rs2976392 SNP and GCa risk in a dominant genetic model.
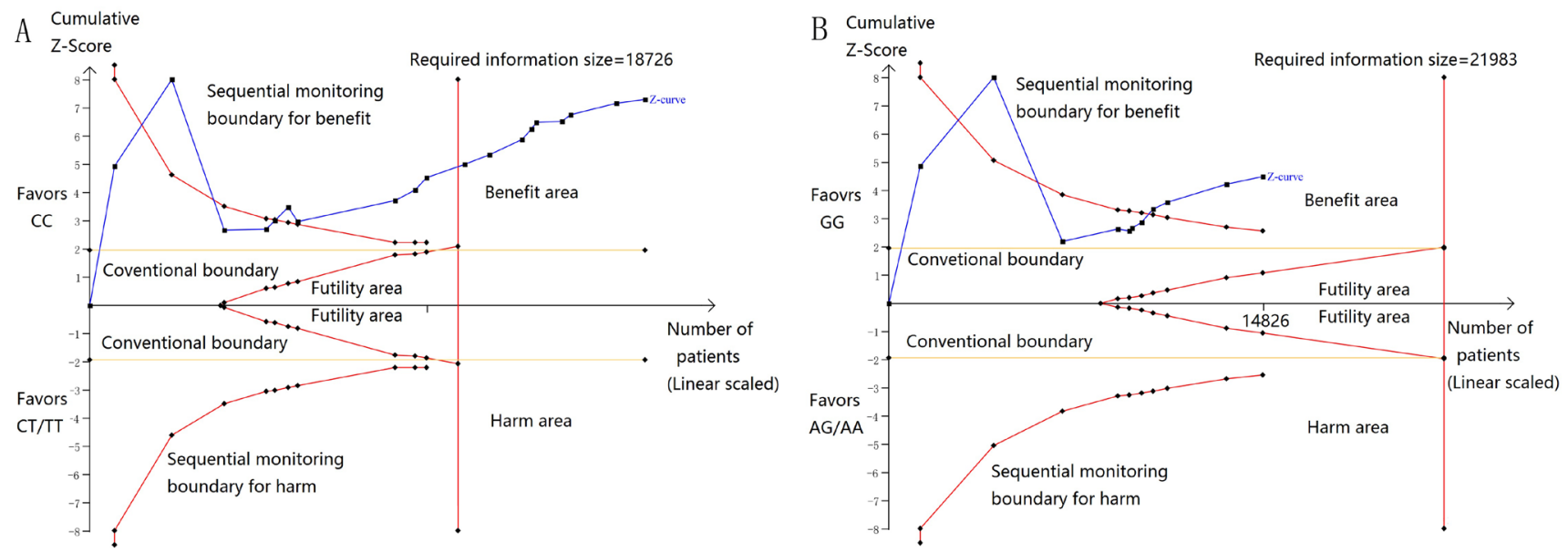

Figure 3: A. Sequential meta-analysis for dominant models for rs 2294008 , with relative risk reduction of $10 \%$, power of $80 \%$, alpha of $5 \%$, and heterogeneity correction of $78.75 \%$. Sequential boundary for benefit has been crossed and the required information size was satisfied. B. Sequential meta-analysis for dominant models for rs 2294008 , with relative risk reduction of $10 \%$, power of $80 \%$, alpha of $5 \%$, and heterogeneity correction of $84.70 \%$. Sequential boundary for benefit has been crossed. 
Moreover, it was reported that the expression of PSCA may be coming from some proliferating precursor cells [43]. These findings suggested that PSCA is a potential tumor suppressor in GCa. Therefore, it is biologically plausible that SNPs that lead to down-regulate expression of PSCA make individuals predisposed to GCa. This speculative hypothesis is consistent with or supported by our results that the PSCA rs2294008 T and rs2976392 A alleles were associated with an increased GCa risk in the study population. More importantly, these associations were further validated by our meta-analysis with pooled data from all the published studies. Also, results of most pooled data were considered to be robust by sequential meta-analysis, except for rs2294008 with heterogenous results across studies $\left(I^{2}=95.90 \%\right)$.

However, it was surprising that GCa risk for the subgroups of PSCA homozygotes (TT for rs2294008 and AA for rs2297692) were not statistically significant. This may be explained by a co-dominant genetic model, in which only the imbalanced paired protein subunits coded by the two different alleles will have an effect on the proteins' functions; alternatively, the variant homozygotes may have experienced embryo lethal events, leading to a high rate of abortions; lastly, this finding may be simply due to chance, because of a systemic error in genotyping or because the small sample size of the subgroup may have insufficient statistical power to detect a weak effect or may have generated an unstable risk estimate. All these speculations should be further explored in future larger and mechanistic studies. Therefore, our results should be interpreted with caution.

There are some limitations in the present study. First, although age, sex, smoking and drinking status, and tumor site were taken into consideration for subgroup analysis, other important risk factors such as diet and HP infection, which were missing in this study, might also contribute to the etiology of GCa. Second, new classification of GCa tumor types, which was not available for the patients diagnosed years ago, is also important, which may have a different genetic basis in the etiology. Third, the sample size of the cases in subgroups was largely reduced in the stratification analysis, which may have led to limited statistical power in subsequent analysis.

In summary, our results indicated that the PSCA rs2294008 T and rs2976392 A alleles may be lowpenetrate risk factors for $\mathrm{GCa}$. However, future studies should incorporate diet, HP infection status and Lauren classification to better understand the associations between the PSCA SNPs and GCa risk.

\section{MATERIALS AND METHODS}

\section{Study subjects}

This study included GCa patients and cancerfree controls who were part of our ongoing molecular epidemiology study as described previously [19-21]. Briefly, 1,125 unrelated ethnic Han Chinese patients with newly diagnosed and histopathologically confirmed primary $\mathrm{GCa}$ were recruited from Fudan University Shanghai Cancer Center (FUSCC) in Eastern China between January 2009 and March 2011. Patients other than histopathologically confirmed primary GCa were excluded. In addition, 1,196 age and sex-matched cancerfree ethnic Han Chinese controls were recruited from the Taizhou Longitudinal (TZL) study conducted at the same time period in Eastern China as described previously [22]. Blood samples of GCa patients and cancer-free controls were provided by the tissue banks of FUSCC and the TZL study, respectively. All subjects had signed a written informed consent for donating their biological samples to the tissue banks for scientific research. Demographic data and environmental exposure history of each subject were collected. The overall response rate was approximately $91 \%$ for cases and $90 \%$ for controls. This research protocol was approved by the FUSCC institutional review board.

\section{SNP genotyping}

Using to a standard protocol, we extracted genomic DNA from peripheral blood samples. The rs2294008 and rs2976392 SNPs were genotyped by the TaqMan assay with the ABI7900HT real-time PCR system as reported previously [19]. Subjects' case-control status was unrevealed in the genotyping process. As recommend by the company, four negative controls (without a DNA template) and two duplicated samples were included in each of 384-plates for the quality control. The assays were repeated for $5 \%$ of the samples, and the results were $100 \%$ concordant.

\section{Statistical methods}

An individual who never smoked cigarettes was defined as a never smoker; who smoked cigarettes but quit more than one year before diagnosis (for cases) or before the interview (for controls) was defined as a former smoker; and who smoked currently or quit within one year before diagnosis (for cases) or before the interview (for controls) was defined as a current smoker. Ever smokers included both former smokers and current smokers. Those who drank alcoholic beverages at least once a week for one year or more were defined as drinkers, while the 
others were non-drinkers. The $\chi^{2}$ test was used to assess the differences in the distributions of demographic characteristics between cases and controls. The associations between SNPs and GCa risk were assessed by odds ratios (ORs) and 95\% confidence intervals (CIs) in heterozygous, homogenous, and dominant models. ORs were calculated by univariate and multivariate logistic regression models. Logistic regression models were used to test for each genetic model with adjustment for age, sex, smoking and drinking status. The combined effect of the tested SNPs on GCa risk was also evaluated in logistic models. Furthermore, associations between the PSCA rs2294008 C > T and rs2976392 G>A SNPs and GCa risk were stratified by age, sex, smoking or drinking status, and primary tumor site. All the statistical processes were performed by using SAS software (version 9.1; SAS Institute, Cary, NC)

To further validate our results, we also performed a mini meta-analysis with studies searched from Medline, PubMed and Embase. Principles in search terms and inclusion and exclusion criteria were basically in accordance with previous studies [23, 24]. All primary reports were carefully reviewed, and the relevant references in these papers were also manually searched and reviewed by two independent authors. Then, data were retrieved form included studies and pooled ORs for heterozygous, homozygous, and dominant models were calculated. Heterogeneity among studies was estimated by Chi-square-based $\mathrm{Q}$ test. A $P$ value greater than 0.10 for the Q-test indicates a lack of heterogeneity among studies, so the pooled OR estimate of the each study was calculated by the fixed-effects model (the MantelHaenszel method). Otherwise, the random-effects model (the DerSimonian and Laird method) was used [25]. To validate the stability of the pooled results and find the sources of heterogeneity, we performed the leave-oneout sensitive analysis. Publication bias was shown by the funnel plot, in which the asymmetry was estimated by the Egger's liner regression test, where the statistically significant publication bias was tested out when a $P<0.05$ determined by the $t$ test was suggested by Egger. All the statistical processes were achieved by using STATA version 10.0 (Stata Corporation, College Station, TX). Whether results were conclusive could not be answered by traditional meta-analysis without keeping and balancing the type I and type II error. To address this problem, studies included in this meta-analysis were analogous to interim randomized controlled clinical trials. Sequential metaanalysis (SMA) was conducted to calculate the required information size in this meta-analysis. Lan DeMets sequential monitoring boundary was established to control the type I and II error by alpha and beta-spending function methods. Whether the monitoring boundary was crossed was used as a way to estimate the reliability of the results acquired from traditional meta-analysis. All steps were accomplished with the TSA software version 0.9 .

\section{ACKNOWLEDGMENTS}

This study was supported by grant from the National Natural Science Foundation of China (81101808 and 81502046), the grant from "China's Thousand Talents Program" Recruitment at Fudan University, the Special Financial Grant from the China Postdoctoral Science Foundation (Grant No. 2014T70836), and the grant from the Ministry of Health (201002007).

\section{CONFLICTS OF INTEREST}

None declared.

\section{REFERENCES}

1. Torre LA, Bray F, Siegel RL, Ferlay J, Lortet-Tieulent J and Jemal A. Global cancer statistics, 2012. CA Cancer J Clin. 2015; 65:87-108.

2. Ye W, Held M, Lagergren J, Engstrand L, Blot WJ, McLaughlin JK and Nyren O. Helicobacter pylori infection and gastric atrophy: risk of adenocarcinoma and squamouscell carcinoma of the esophagus and adenocarcinoma of the gastric cardia. J Natl Cancer Inst. 2004; 96:388-396.

3. Ishaq S and Nunn L. Helicobacter pylori and gastric cancer: a state of the art review. Gastroenterology and hepatology from bed to bench. 2015; 8:S6-S14.

4. Woo HD, Lee J, Choi IJ, Kim CG, Lee JY, Kwon O and Kim J. Dietary flavonoids and gastric cancer risk in a Korean population. Nutrients. 2014; 6:4961-4973.

5. Wang Z, Dai J, Hu N. Identification of new susceptibility loci for gastric non-cardia adenocarcinoma: pooled results from two Chinese genome-wide association studies. Gut.2015; doi:10.1136/gutjnl-2015-310612.

6. Abnet CC, Freedman ND, Hu N, Wang Z, Yu K, Shu XO, Yuan JM, Zheng W, Dawsey SM, Dong LM, Lee MP, Ding T, Qiao YL, et al. A shared susceptibility locus in PLCE1 at 10q23 for gastric adenocarcinoma and esophageal squamous cell carcinoma. Nat Genet. 2010; 42:764-767.

7. Mocellin S, Verdi D, Pooley KA and Nitti D. Genetic variation and gastric cancer risk: a field synopsis and metaanalysis. Gut. 2015; 64:1209-1219.

8. Qiu LX, He J, Cheng L, Zhou F, Wang MY, Sun MH, Zhou XY, Li J, Guo WJ, Wang YN, Yang YJ, Wang JC, Jin L, Zhu XD, Wei QY. Genetic variant of PRKAA1 and gastric cancer risk in an eastern Chinese population. Oncotarget. 2015; 15;6:42661-426666. doi: 10.18632/oncotarget.6124.

9. Shi Y, Hu Z, Wu C, Dai J, Li H, Dong J, Wang M, Miao X, Zhou Y, Lu F, Zhang H, Hu L, Jiang Y, Li Z, Chu M, Ma H. A genome-wide association study identifies new susceptibility loci for non-cardia gastric cancer at 3q13.31 and 5p13.1. Nat Genet. 2011; 43:1215-1218.

10. Tran CP, Lin C, Yamashiro J and Reiter RE. Prostate stem cell antigen is a marker of late intermediate prostate 
epithelial cells. Mol Cancer Res. 2002; 1:113-121.

11. Hruska M, Keefe J, Wert D, Tekinay AB, Hulce JJ, IbanezTallon I and Nishi R. Prostate stem cell antigen is an endogenous lynx1-like prototoxin that antagonizes alpha7containing nicotinic receptors and prevents programmed cell death of parasympathetic neurons. J Neurosci. 2009; 29:14847-14854.

12. Bahrenberg G, Brauers A, Joost HG and Jakse G. Reduced expression of PSCA, a member of the LY-6 family of cell surface antigens, in bladder, esophagus, and stomach tumors. Biochem Biophys Res Commun. 2000; 275:783788.

13. Sakamoto H, Yoshimura K, Saeki N, Katai H, Shimoda T, Matsuno Y, Saito D, Sugimura H, Tanioka F, Kato S, Matsukura N, Matsuda N, Nakamura T, et al. Genetic variation in PSCA is associated with susceptibility to diffuse-type gastric cancer. Nat Genet. 2008; 40:730-740.

14. Ono H, Hiraoka N, Lee YS, Woo SM, Lee WJ, Choi IJ, Saito A, Yanagihara K, Kanai Y, Ohnami S, Chiwaki F, Sasaki H, Sakamoto H, Yoshida T and Saeki N. Prostate stem cell antigen, a presumable organ-dependent tumor suppressor gene, is down-regulated in gallbladder carcinogenesis. Genes, chromosomes \& cancer. 2012; 51:30-41.

15. Wu X, Ye Y, Kiemeney LA, Sulem P, Rafnar T, Matullo G, Seminara D, Yoshida T, Saeki N, Andrew AS, Dinney CP, Czerniak B, Zhang ZF, et al. Genetic variation in the prostate stem cell antigen gene PSCA confers susceptibility to urinary bladder cancer. Nat Genet. 2009; 41:991-995.

16. Tanikawa C, Urabe Y, Matsuo K, Kubo M, Takahashi A, Ito H, Tajima K, Kamatani N, Nakamura Y and Matsuda K. A genome-wide association study identifies two susceptibility loci for duodenal ulcer in the Japanese population. Nat Genet. 2012; 44:430-434.

17. Lu Y, Chen J, Ding Y, Jin G, Wu J, Huang H, Deng B, Hua Z, Zhou Y, Shu Y, Liu P, Hu Z, Shen J, Xu Y and Shen $\mathrm{H}$. Genetic variation of PSCA gene is associated with the risk of both diffuse- and intestinal-type gastric cancer in a Chinese population. Int J Cancer. 2010; 127:2183-2189.

18. Wu C, Wang G, Yang M, Huang L, Yu D, Tan W and Lin D. Two genetic variants in prostate stem cell antigen and gastric cancer susceptibility in a Chinese population. Mol Carcinog. 2009; 48:1131-1138.

19. He J, Qiu LX, Wang MY, Hua RX, Zhang RX, Yu HP, Wang YN, Sun MH, Zhou XY, Yang YJ, Wang JC, Jin L, Wei QY and Li J. Polymorphisms in the XPG gene and risk of gastric cancer in Chinese populations. Human genetics. 2012; 131:1235-1244.

20. He J, Xu Y, Qiu LX, Li J, Zhou XY, Sun MH, Wang JC, Yang YJ, Jin L, Wei QY and Wang Y. Polymorphisms in ERCC1 and XPF genes and risk of gastric cancer in an eastern Chinese population. PloS one. 2012; 7:e49308.

21. He J, Wang MY, Qiu LX, Zhu ML, Shi TY, Zhou XY, Sun MH, Yang YJ, Wang JC, Jin L, Wang YN, Li J, Yu
HP and Wei QY. Genetic variations of mTORC1 genes and risk of gastric cancer in an Eastern Chinese population. Mol Carcinogen. 2013; 52 Suppl 1:E70-79.

22. Wang X, Lu M, Qian J, Yang Y, Li S, Lu D, Yu S, Meng W, Ye W and Jin L. Rationales, design and recruitment of the Taizhou Longitudinal Study. BMC Public Health. 2009; 9:223.

23. Qiu LX, Zhang J, Zhu XD, Zheng CL, Sun S, Wang ZH, Zhao XM, Wang JL, Wang LP, Yu H, Xue K and Hu XC. The p21 Ser31Arg polymorphism and breast cancer risk: a meta-analysis involving 51,236 subjects. Breast Cancer Res Treat. 2010; 124:475-479.

24. Zhu J, Wang M, Zhu M, He J, Wang JC, Jin L, Wang XF, Xiang JQ and Wei Q. Associations of PI3KR1 and mTOR polymorphisms with esophageal squamous cell carcinoma risk and gene-environment interactions in Eastern Chinese populations. Scientific reports. 2015; 5:8250-8260.

25. Zintzaras E and Ioannidis JP. Heterogeneity testing in metaanalysis of genome searches. Genetic epidemiology. 2005; 28:123-137.

26. Sakamoto H, Yoshimura K, Saeki N, Katai H, Shimoda T, Matsuno Y, Saito D, Sugimura H, Tanioka F, Kato S, Matsukura N, Matsuda N, Nakamura T, et al. Genetic variation in PSCA is associated with susceptibility to diffuse-type gastric cancer. Nat Genet. 2008; 40:730-740.

27. Ou J, Li K, Ren H, Bai H, Zeng D and Zhang C. Association and haplotype analysis of prostate stem cell antigen with gastric cancer in Tibetans. DNA Cell Biol. 2010; 29:319323.

28. Lochhead P, Frank B, Hold GL, Rabkin CS, Ng MT, Vaughan TL, Risch HA, Gammon MD, Lissowska J, Weck MN, Raum E, Muller H, Illig T, et al. Genetic variation in the prostate stem cell antigen gene and upper gastrointestinal cancer in white individuals. Gastroenterology. 2011; 140:435-441.

29. Song HR, Kim HN, Piao JM, Kweon SS, Choi JS, Bae WK, Chung IJ, Park YK, Kim SH, Choi YD and Shin MH. Association of a common genetic variant in prostate stemcell antigen with gastric cancer susceptibility in a Korean population. Mol Carcinog. 2011; 50:871-875.

30. Zeng Z, Wu X, Chen F, Yu J, Xue L, Hao Y, Wang Y, Chen M, Sung JJ and Hu P. Polymorphisms in prostate stem cell antigen gene rs2294008 increase gastric cancer risk in Chinese. Mol Carcinog. 2011; 50:353-358.

31. Li F, Zhong MZ, Li JH, Liu W and Li B. Case-control study of single nucleotide polymorphisms of PSCA and MUC1 genes with gastric cancer in a Chinese. Asian Pac J Cancer Prev. 2012; 13:2593-2596.

32. Sala N, Munoz X, Travier N, Agudo A, Duell EJ, Moreno V, Overvad K, Tjonneland A, Boutron-Ruault MC, ClavelChapelon F, Canzian F, Kaaks R, Boeing H, et al. Prostate stem-cell antigen gene is associated with diffuse and intestinal gastric cancer in Caucasians: results from the EPIC-EURGAST study. Int J Cancer. 2012; 130:2417- 
2427.

33. Rizzato C, Kato I, Plummer M, Munoz N and Canzian F. Genetic variation in PSCA and risk of gastric advanced preneoplastic lesions and cancer in relation to Helicobacter pylori infection. PLoS One. 2013; 8:e73100.

34. Zhao J, Geng P, Li Z, Cui S, Wang L, Li J, Ji F, Li G, Shen G, Lin M and Shen C. Prostate stem cell antigen rs2294008 polymorphism differentially contributes to -negative gastric cancer among various populations in China. Mol Clin Oncol. 2013; 1:493-498.

35. Sun Y, Gu J, Ajani JA, Chang DW, Wu X and Stroehlein JR. Genetic and intermediate phenotypic susceptibility markers of gastric cancer in Hispanic Americans: a casecontrol study. Cancer. 2014; 120:3040-3048.

36. Kupcinskas J, Wex T, Link A, Bartuseviciute R, Dedelaite M, Kevalaite G, Leja M, Skieceviciene J, Kiudelis G, Jonaitis L, Kupcinskas L and Malfertheiner P. PSCA and MUC1 gene polymorphisms are linked with gastric cancer and pre-malignant gastric conditions. Anticancer Res. 2014; 34:7167-7175.

37. Sun H, Wu X, Wu F, Li Y, Yu Z, Chen X, Chen Y and Yang W. Associations of genetic variants in the PSCA, MUC1 and PLCE1 genes with stomach cancer susceptibility in a Chinese population. PLoS One. 2015; 10:e117576.

38. Ichikawa H, Sugimoto M, Uotani T, Sahara S, Yamade M, Iwaizumi M, Yamada T, Osawa S, Sugimoto K, Miyajima $\mathrm{H}$, Yamaoka Y and Furuta T. Influence of Prostate Stem Cell Antigen Gene Polymorphisms on Susceptibility to Helicobacter pylori-associated Diseases: A Case-control Study. Helicobacter. 2015; 20:106-113.

39. Garcia-Gonzalez MA, Bujanda L, Quintero E, Santolaria S, Benito R, Strunk M, Sopena F, Thomson C, Perez-Aisa A, Nicolas-Perez D, Hijona E, Carrera-Lasfuentes P, Piazuelo E, Jimenez P, Espinel J, Campo R. Association of PSCA rs2294008 gene variants with poor prognosis and increased susceptibility to gastric cancer and decreased risk of duodenal ulcer disease. Int J Cancer. 2015;137:1362-1373.

40. Shen G, Zhang C, Zhao J, Geng P, Dou L, Zhang S, Ma D and Li G. A study of relationship between PSCA gene polymorphisms and susceptibility to Tibetan gastric cancer in Qinghai area. Journal of Qinghai Medical College. 2011; 32:169-171.

41. Ju YF, Diao YQ, Song MQ and Jiang XJ. PSCA polymorphism rs2976392 in gastric cancer. Chinese Journal of Oncology Prevention and Treatment. 2013; 5:300-303.

42. Wang B, Pang C, Yang G, Ren J, Wang H and Wang Y. An association study of SNP rs2976392 in PSCA gene and gastric cancer. Journal of Baotou Medical College. 2014; 30:1-2.

43. Karam SM, Straiton T, Hassan WM and Leblond CP. Defining epithelial cell progenitors in the human oxyntic mucosa. Stem cells. 2003; 21:322-336. 